\title{
Retraction
}

\section{Retracted: Immunopathology and Immunogenetics of Allergic Bronchopulmonary Aspergillosis}

\author{
Journal of Allergy \\ Received 19 August 2015; Accepted 19 August 2015 \\ Copyright (C) 2015 Journal of Allergy. This is an open access article distributed under the Creative Commons Attribution License, \\ which permits unrestricted use, distribution, and reproduction in any medium, provided the original work is properly cited.
}

The paper titled "Immunopathology and Immunogenetics of Allergic Bronchopulmonary Aspergillosis" [1], published in Journal of Allergy, has been retracted as it was found to contain a substantial amount of material from the following published article: "Allergic bronchopulmonary aspergillosis in asthma and cystic fibrosis" published in Clinical and Developmental Immunology, vol. 2011, Article ID 843763, 13 pages, 2011, DOI: 10.1155/2011/843763.

\section{References}

[1] A. P. Knutsen, "Immunopathology and immunogenetics of allergic bronchopulmonary aspergillosis," Journal of Allergy, vol. 2011, Article ID 785983, 9 pages, 2011. 


\section{Immunopathology and Immunogenetics of Allergic} Bronchopulmonary Aspergillosis

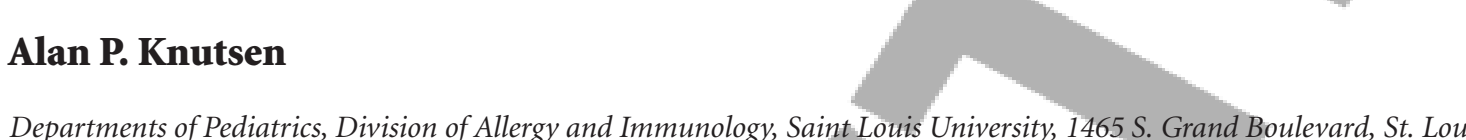

Departments of Pediatrics, Division of Allergy and Immunology, Saint Louis University, 1465 S. Grand Boulevard, St. Louis, Mo 63104, USA

Correspondence should be addressed to Alan P. Knutsen, knutsenm@slu.edu

Received 3 May 2011; Accepted 14 July 2011

Academic Editor: Prescott Woodruff

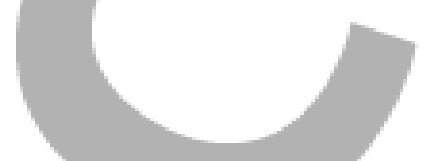

Copyright ( 2011 Alan P. Knutsen. This is an open access article distributed under the Creative Commons Attribution License, which permits unrestricted use, distribution, and reproduction in any medium, provided the original work is properly cited.

Allergic bronchopulmonary aspergillosis (ABPA) is a Th2 hypersensitivity lung disease in response to Aspergillus fumigatus that affects asthmatic and cystic fibrosis (CF) patients. Sensitization to A. fumigatus is common in both atopic asthmatic and CF patients, yet only $1 \%-2 \%$ of asthmatic and $7 \%-9 \%$ of CF patients develop ABPA. ABPA is characterized by wheezing and pulmonary infiltrates which may lead to pulmonary fibrosis and/or bronchiectasis. The inflammatory response is characterized by Th2 responses to Aspergillus allergens, increased serum IgE, and eosinophilia. A number of genetic risks have recently been identified in the development of ABPA. These include HLA-DR and HLA-DQ, IL-4 receptor alpha chain (IL-4RA) polymorphisms, $I L-10-1082 G A$ promoter polymorphisms, surfactant protein A2 (SP-A2) polymorphisms, and cystic fibrosis transmembrane conductance regulator gene (CFTR) mutations. The studies indicate that ABPA patients are genetically at risk to develop skewed and heightened Th2 responses to A. fumigatus antigens. These genetic risk studies and their consequences of elevated biologic markers may aid in identifying asthmatic and CF patients who are at risk to the development of ABPA. Furthermore, these studies suggest that immune modulation with medications such as anti-IgE, anti-IL-4, and/or IL-13 monoclonal antibodies may be helpful in the treatment of ABPA.

\section{Introduction}

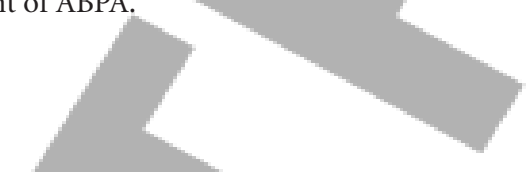

Allergic bronchopulmonary aspergillosis (ABPA) is a hypersensitivity lung disease due to bronchial colonization by Aspergillus fumigatus that occurs in susceptible patients with asthma and cystic fibrosis (CF). The first published description of ABPA as an entity came from the United Kingdom in 1952 [1], while the first cases in the United States were reported a decade later $[2,3]$. ABPA affects approximately $1 \%-2 \%$ of asthmatic patients and $7 \%-9 \%$ of CF patients [4-6]. If unrecognized or poorly treated, ABPA leads to airway destruction, bronchiectasis, and/or pulmonary fibrosis, resulting in significant morbidity and mortality.

The diagnosis of ABPA is based on clinical and immunologic reactivity to $A$. fumigatus. The minimal criteria required for the diagnosis of ABPA are: (1) asthma or cystic fibrosis with deterioration of lung function, for example, wheezing, (2) immediate Aspergillus skin test reactivity, (3) total serum $\mathrm{IgE} \geq 1000 \mathrm{IU} / \mathrm{mL}$, (4) elevated Aspergillus specific IgE and
IgG antibodies, and (5) chest radiographic infiltrates. Additional criteria may include peripheral blood eosinophilia, Aspergillus serum precipitating antibodies, central bronchiectasis, and Aspergillus containing mucus plug production [7-11]. The designation of ABPA-seropositive (ABPA-S) may be used to classify asthmatic patients who meet the required criteria but lack the proximal or central bronchiectasis (ABPA-CB). High-resolution computed tomography (HRCT) may demonstrate central bronchiectasis in the inner two thirds of the field even in the absence of chest radiograph lesions. The clinician should note that the development of ABPA is not dependent on asthma severity. The diagnosis of ABPA in CF is more complicated and disagreement exists in the literature regarding the diagnostic criteria. The difficulty lies in the fact that the usual criteria for ABPA and the common signs and symptoms of CF overlap. The most recent Cystic Fibrosis Foundation Consensus Conference proposed the following diagnostic criteria: (1) acute or subacute pulmonary deterioration not attributable to another etiology, 
(2) total serum IgE $>1000 \mathrm{IU} / \mathrm{mL}$, (3) immediate cutaneous reactivity to Aspergillus or in vitro specific IgE antibodies to Aspergillus, and (4) one of the following: Aspergillus serum precipitins, elevated specific IgG anti-Aspergillus antibodies, new or recent chest radiographic, or chest $\mathrm{CT}$ abnormalities that have not cleared with antibiotics and chest physiotherapy [12].

1.1. Radiographic and Laboratory Investigations. There are several characteristic radiographic abnormalities associated with ABPA [7-11]. The most common lesion is a large, homogeneous shadow in one of the upper lobes with no change in volume. The shadow may be triangular, lobar, or patchy, and it frequently moves to another site. "Tram-line" shadows are fine parallel lines radiating from the hila that represent inflammation of airway walls. Mucoid impaction causes toothpaste shadows or gloved-finger shadows, which can be seen on plain radiograph.

Adult patients have been reported with normal chest radiographs so radiographic abnormalities are not invariably present. In these individuals, HRCT scan may reveal central cylindrical bronchiectasis even in the absence of chest radiograph abnormalities. Sometimes, "tree-in-bud pattern" may been seen on HRCT scan that indicates some degree of airway mucus plugging. It is more commonly considered evidence of atypical mycobacterial infection and may be seen in cystic fibrosis. However, central bronchiectasis is a common complication and finding in all CF patients.

Laboratory tests that support the diagnosis of ABPA are those that demonstrate allergy to the A. fumigatus, such as elevated specific IgE anti-Aspergillus antibodies and positive Aspergillus precipitins [7-11]. Culture of A. fumigatus from the sputum is only a secondary criterion for the diagnosis of ABPA, because a large proportion of individuals with CF without ABPA have Aspergillus on sputum cultures. Some normal individuals and many individuals with lung diseases have small numbers of spores in their sputum; these are probably present because of passive inhalation. The presence of hyphae is more specific, and the presence of eosinophils in association with hyphal elements is suggestive of the diagnosis. At the time of radiographic exacerbation, the presence of eosinophilia in sputum or blood is suggestive of ABPA in asthmatics and is a primary diagnostic criterion. The peripheral blood eosinophil count is usually greater than $1000 / \mathrm{mm}^{3}$, and values greater than $3000 / \mathrm{mm}^{3}$ are common. Eosinophilia is not a diagnostic criteria of ABPA in CF patients. In the authors' experience, eosinophilia is an uncommon finding in CF ABPA patients.

An increased total serum IgE level is very characteristic of ABPA, and values may reach as high as $30,000 \mathrm{IU} / \mathrm{mL}$. Usually, the level is greater than $1000 \mathrm{IU} / \mathrm{mL}$. Much of the $\mathrm{IgE}$ is not specific to Aspergillus but is the result of polyclonal B-cell activation. The IgE level is a very useful marker of disease activity, and it can be used to follow outpatients for "flares". The simple skin-prick test is a useful screening test, as ABPA is very unlikely in patients with a negative reaction. A dual-reaction skin test with an immediate (1015 minutes) and a late (4-8 hours) reaction may occur but is uncommon in ABPA. Alternatively, serum may be measured for the presence of specific IgE and IgG antibodies. Patients with Aspergillus-sensitive asthma will generally have elevated Aspergillus-specific IgE antibodies, but patients with ABPA will have much higher Aspergillus-specific IgE levels. Hemmann et al. [13] reported that ABPA and Aspergillussensitive patients have elevated IgE antibodies to recombinant Aspergillus Asp f1, Asp f3, Asp f4, and Asp f6 allergens and that IgE levels to Asp f4 and Asp f6 is highly specific for ABPA in CF patients.

Differentiating between a bacterial flare versus an ABPA flare in CF patients may be difficult. A useful serum biologic marker may be thymus and activation-regulated chemokine (TARC) or CCL17. Latzin et al. [14] and Hartl et al. [15] reported that TARC was elevated in CF patients with ABPA and was further elevated during acute flares of ABPA. TARC is a chemokine whose ligand is CCR4 receptor on $\mathrm{CD} 4^{+} \mathrm{Th} 2$ cells.

In ABPA, immunoelectrophoresis generally shows one to three precipitin lines, often to only one extract [7-11]. Patients with aspergilloma will have multiple precipitin lines to all antigen extracts. Extracts of A. fumigatus contain a complex mixture of proteins that are mainly derived from the hyphae. Antigenic composition varies between batches according to the culture conditions even within the same laboratory. There is, therefore, a lack of standardization that makes it difficult to compare results between laboratories. There are 22 recognized recombinant allergens by the International Union of Immunological Societies. With purification of these major antigenic components, this may lead to improved diagnosis.

1.2. Pulmonary Pathology of ABPA. The gross pathology of ABPA demonstrates cylindrical bronchiectasis of the central airways, particularly those to the upper lobes [7-11]. These airways may be occluded by "mucoid impaction," a condition in which large airways are occluded by impacted mucus and hyphae. Airway occlusion may lead to atelectasis of a segment or lobe and, if the atelectasis is long-standing, saccular bronchiectasis may result. Typically, ABPA is worse in the upper lobes than in the lower lobes. Microscopic examination of the airways shows infiltration of the airway wall with eosinophils, lymphocytes, and plasma cells. The airway lumen may be occluded by mucus containing hyphal elements and inflammatory cells, especially eosinophils. Squamous metaplasia of the bronchial mucosa commonly develops, and granulomas may form. Rarely, bronchiolitis obliterans or bronchocentric granulomatosis develops.

\section{Immunopathogenesis of ABPA}

As seen in Figure 1, the pathogenesis of ABPA in susceptible persons begins with the inhalation of $A$. fumigatus spores that germinate into hyphae deep within the bronchi. Fragments of hyphae have also been found within the lung parenchyma, potentially resulting in high concentrations of Aspergillus allergens exposed to the respiratory epithelium and immune system [16-19]. These allergens are processed by HLA-DR2 or HLA-DR5 bearing antigen presenting cells (APCs) and presented to $\mathrm{T}$ cells within bronchoalveolar lymphoid tissue 


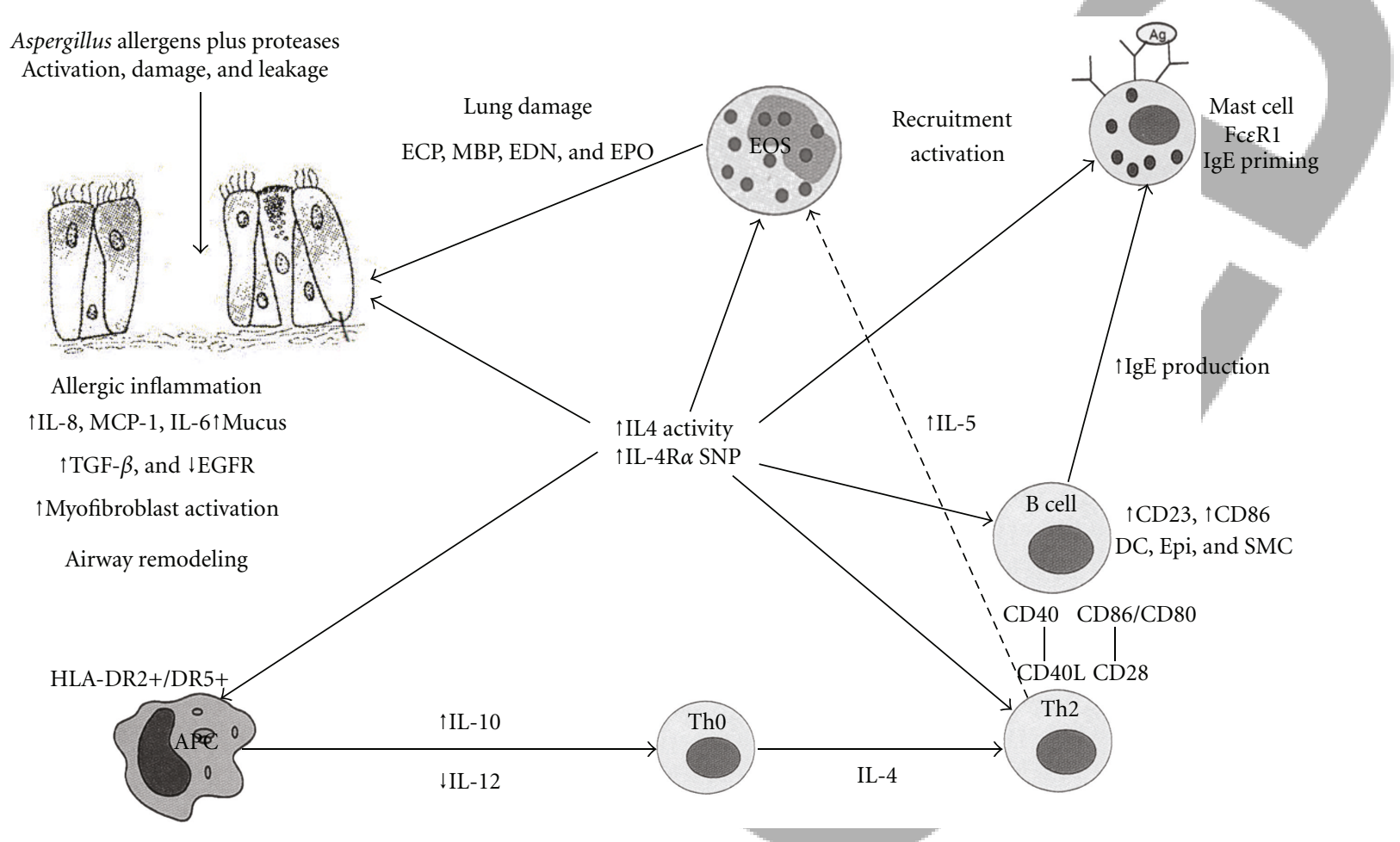

FIgure 1: Proposed immunopathogenesis of ABPA. In the pathogenesis of ABPA, A. fumigatus proteases have a direct effect on bronchial epithelia causing epithelial cell damage with subsequent stimulation of cytokines and chemokines. Aspergillus proteins are processed via HLA-DR2/DR5 bearing dendritic cells that skew the Th0 response to a Th2 response. Th2 cytokines stimulate IgE synthesis and eosinophil activation. This leads to an eosinophilic inflammatory in the bronchial airways.

(BALT). The resulting $\mathrm{CD} 4^{+} \mathrm{T}$ cell responses to Aspergillus are skewed toward Th2 response with the production of IL4, IL-5, and IL-13 cytokines.

2.1. Effect of Aspergillus on Bronchial Epithelium. A. fumigatus spores 3 to $5 \mu \mathrm{m}$ in size are inhaled and germinate deep within the bronchi into hyphae [17]. In addition, fragments of the hyphae can be identified within the interstitial of the pulmonary parenchyma. The implication of this is that there is the potential for high concentrations of A. fumigatus allergens exposed to the respiratory epithelium and immune system. A. fumigatus releases a variety of proteins, including superoxide dismutases, catalases, proteases, ribotoxin, phospholipases, hemolysin, gliotoxin, phthioic acid, and other toxins. The first line of defense against Aspergillus colonization in the lungs is macrophage and neutrophil killing of the conidia and the hyphae. In the development of ABPA, Kauffman's group proposed that Aspergillus proteins have a direct effect on the pulmonary epithelia and macrophage inflammation $[20,21]$. They demonstrated that Aspergillus proteases induce epithelial cell detachment. In addition, protease-containing culture filtrates of Aspergillus induce human bronchial cell lines to produce proinflammatory chemokines and cytokines, such as IL-8, IL-6, and MCP-1. Thus, various Aspergillus proteins have significant biologic activity that disrupts the epithelial integrity and induces a monokine inflammatory response. This protease activity is thought to allow for enhanced allergen exposure to the bronchoalveolar lymphoid tissue immune system. This is evident by the bronchoalveolar lymphoid tissue synthesis of Aspergillus-specific IgE and IgA antibodies.

An important pathogenic feature of Aspergillus and other microbes is their ability to interact with epithelial cells on the mucosal surface. Macrophage and neutrophil killing of the conidia and hyphae is the first line of defense against colonization in the lungs [12, 22-24]. This is evidenced by an increased susceptibility to invasive pulmonary aspergillosis in patients with chronic granulomatous disease, a disorder of phagocyte killing. A. fumigatus has several virulence factors, including proteolytic enzymes that can interfere with humoral and cellular defense in the airways $[25,26]$. Proteases from Aspergillus and other fungi, including Alternaria and Cladosporium, have been shown to cause epithelial cell detachment though Aspergillus proteases demonstrated more activity at lower concentrations [25-28].

In addition to damaging the integrity of the epithelial cell layer, Kauffman's group demonstrated that protease containing culture infiltrates of $A$. fumigatus induced human bronchial cell lines to produce proinflammatory chemokines and cytokines, such as monocyte chemoattractant protein (MCP)-1, IL-8, and IL-6 [20]. MCP-1 has been implicated in directly stimulating the development of Th2 cells [29]. The cytokine-release activity could be ascribed to the proteolytic activities of these extracts $[20,27]$. These observations suggested that proteolytic enzymes released by Aspergillus, growing on and between epithelial cells, were responsible for 
the induction of chemoattractive cytokines by epithelial cells and the corresponding inflammation. It was proposed that the induction of the severe inflammatory responses by the direct activation of epithelial cells may cause additional harm to the epithelial cell layer [25]. Destruction of the epithelial cell barrier either by fungal proteases or eosinophilic and neutrophilic inflammation was followed by repair mechanisms, resulting in the influx of serum proteins and extracellular matrix proteins to the luminal side of the epithelium [30]. Because spores and mycelium of A. fumigatus have surface structures that are able to interact with extracellular matrix molecules, damage and repair mechanisms of the airway mucosa may facilitate the binding of Aspergillus to the damaged sites of the airways. The enhanced release of proteolytic enzymes and allergens on the epithelial surface would induce a continuous inflammatory response and mast cell degranulation, resulting in severe and longlasting periods of exacerbations of ABPA.

2.2. Aspergillus-Specific Th2 Cells. The immune response to Aspergillus antigens in ABPA patients, as well as allergic asthmatic and CF patients, is characterized by a Th2 $\mathrm{CD} 4^{+}$ T lymphocyte response $[17,31-35]$. Skin test reactivity to Aspergillus is found in $20 \%-25 \%$ of asthmatic patients [5, $36,37]$ and $31 \%-59 \%$ of CF patients [13, 38]. Although sensitization is common in these populations, only a small percentage of patients develop ABPA.

Several groups have observed $\mathrm{T}$ cell lymphoproliferative responses to crude Aspergillus extracts [31,39-41]. Subsequently, Aspergillus-specific T cell responses were examined and shown to enhance B cell IgE synthesis [41]. In addition, Asp f1 T cell lines were generated, and the phenotypes were found to be $\mathrm{CD}_{4}^{+} \mathrm{CD} 25^{+} \mathrm{T}$ cells with the cytokine profile $\mathrm{IL}-4^{+}$and IFN $\gamma^{-}$, indicating Th2 $\mathrm{CD} 4^{+} \mathrm{T}$ cells [4]. Chauhan et al. [42] subsequently developed $\mathrm{T}$ cell clones from asthmatic ABPA patients and demonstrated either Th2 (IL- $4^{+}$, IFN- $\left.\gamma^{-}\right)$or Th0 $\left(\mathrm{IL}-4^{+}, \mathrm{IFN}-\gamma^{+}\right)$patterns. We demonstrated that ABPA subjects have increased frequency of IL- $4^{+} \mathrm{CD}^{+}$ $\mathrm{T}$ cells from Asp f2/f3/f4-stimulated peripheral blood lymphocytes compared to Aspergillus sensitive non-ABPA subjects [4]. IL-4 produced by T lymphocytes binds to the IL4 receptor (IL-4R) on B cells and in association with the CD40L/CD40 signals, results in IgE isotype switching and B cell proliferation [43]. IL-4 also increases the expression of CD86, which has been linked to eosinophilic airway inflammation and airway hyperresponsiveness after allergen challenge. A central question then is how ABPA patients differ from Aspergillus-sensitive atopic asthmatic and CF patients. We hypothesize that ABPA develops in genetically susceptible individuals with asthma and CF because of increased frequency and/or activity of $A$. fumigatus-specific Th2 $\mathrm{CD}^{+}$cells. We further propose that polymorphisms of the interleukin-4 receptor alpha chain $(I L-4 R A)$ subunit and HLA-DR2/DR5 are the genetic susceptibility risk factors responsible for the development of ABPA.

2.3. IL-4 Responses in ABPA. Human studies and murine models have shown that $\mathrm{CD} 4^{+} \mathrm{Th} 2$ cells and their cytokines are central to the development of ABPA [4, 32-35, 39, 44].
In particular, IL-4 has a key role in the allergic inflammatory response with effects on various cell populations. Its functions include increasing VCAM-1 expression on endothelial cells, which enhances the recruitment of other immune cells, particularly eosinophils, stimulating proliferation of fibroblasts, important in airway remodeling, and increasing Th2 differentiation while decreasing $\mathrm{Th} 1$ differentiation and the production of IFN- $\gamma[45,46]$. IL-4 also has a myriad of effects on B lymphocytes including the stimulation of growth and activation, increasing HLA-DR class II expression important for antigen presentation and inducing cell surface expression of CD23 and soluble CD23. This cell surface molecule is the low affinity $\operatorname{IgE}$ receptor (FcERII) and an activation marker present on a number of cells including B cells, activated $\mathrm{T}$ cells, monocytes, and eosinophils. CD23 plays a role in augmenting B cell IgE synthesis through its interactions with CD21 [47, 48]. Recently, in 2003, anti-CD23 monoclonal antibody was administered to atopic asthmatic subjects and resulted in decreased serum IgE levels [49]. In addition, IL-4 has a more direct role in IgE isotype switching by B-cells. It should be noted that IL-13 may also stimulate the synthesis of IgE and is the only other cytokine that has this capability [ 50 52]. Recently, in 2000 and 2004, increased sensitivity to in vitro IL-4 stimulation as measured by enhanced expression of the low-affinity IgE receptor (CD23) on B cells was observed in ABPA patients $[32,33]$. This was associated with singlenucleotide polymorphisms of the IL-4 receptor alpha chain (IL-4RA) in $92 \%$ of ABPA subjects, principally the IL-4binding single-nucleotide polymorphism ile75val [19, 34, 35]. This increased sensitivity to IL-4 is demonstrated by increased expression of CD23 and CD86 on B cells of ABPA subjects and increased $\mathrm{CD} 23$ expression during flares of ABPA [19]. CD23 is expressed on a variety of cells, including $\mathrm{B}$ cells, natural killer cells, subpopulations of $\mathrm{T}$ cells, and a subpopulation of dendritic cells. T-cell CD23 and B-cell CD21 form a costimulatory pathway. T-cell CD28, B-cells CD80, and CD86 costimulatory pathways activate both $\mathrm{T}$ and B cells, and CD28:CD86 is important in IgE synthesis. CD86 is also found on dendritic cells that have the histamine receptor 2, which skews antigen-specific T cells to a Th2 response. We have also observed increased CD86 expression on monocyte-derived dendritic cells of ABPA subjects. Thus, antigen-presenting cells such as monocytes and dendritic cells bearing HLA-DR2 and/or HLA-DR5 and increased sensitivity to IL-4 stimulation probably play a critical role in skewing A. fumigatus-specific Th2 responses in ABPA.

\section{Immunogenetics of ABPA}

3.1. HLA-DR and HLA-DQ. HLA-DR restriction has been shown to be a risk factor for the development of ABPA (Table 1). Chauhan et al. [42, 53] observed that asthmatic and CF patients who expressed HLA-DR2 and/or DR5 but lacked HLA-DQ2 were at increased risk for ABPA after exposure to A. fumigatus. Within HLA-DR2 and HLA-DR5, there are restricted genotypes. In particular, HLA-DR2 HLADRB1*1501 and HLA-DRB1*1503 genotypes were reported to provide high relative risk. On the other hand, $40 \%$ to $44 \%$ of non-ABPA atopic Aspergillus-sensitive individuals have 
TABLE 1: Genetic risk factors in the development of allergic bronchopulmonary aspergillosis.

(i) HLA-DR restriction and HLA-DQ protection

(a) HLA-DR2 restriction

HLA-DRB ${ }^{*} 1501$ and ${ }^{*}$ HLA-DRB1* 1503

(b) HLA-DR5

HLA-DRB1* 1104

(c) HLA-DQ2 protective, decreased in ABPA

DQB1*0201

(ii) $I L-4 R A$ polymorphisms

(a) $I L-4 R A$ ile75val

(iii) IL-10 polymorphisms

(a) Promoter - 1082 GG genotype

(iv) Surfactant protein A2 (SP-A2) polymorphisms

(a) SP-A2 ala91pro

(v) Cystic fibrosis transmembrane conductance regulator (CFTR) mutations

(a) Heterozygous CFTR mutations in asthmatic patients with ABPA

(vi) Toll-like receptor $(T L R)$ polymorphisms

(a) TLR9 T-1237C polymorphism

the HLA-DR2 and/or DR5 type. Further studies indicated that the presence of HLA-DQ2, especially $\mathrm{DQB1}{ }^{*} 0201$, provided protection from the development of ABPA. Furthermore, Chauhan et al. [42] demonstrated that Asp $\mathrm{fl}$ allergen has a low-affinity of binding to HLA-DR. This is consistent with Th2 $\mathrm{T}$ cell response previously reported by others in that strong antigen HLA-DR-Ag-TCR affinity binding favored a Th1 cellular response, whereas low affinity binding favored a Th2 humoral response [54-58]. Four major $\mathrm{V} \beta$ chains, $\mathrm{V} \beta 3$, 6,13, and 14, reacted to Asp f1.

3.2. IL-4 Alpha Chain Receptor (IL-4RA) Polymorphisms. The IL-4 receptor is a type I cytokine receptor and exists as a heterodimer that shares a subunit, IL-4 receptor alpha chain (IL-4RA), with the IL-13 receptor alpha (IL-13RA) [59]. There are two types of IL-4 receptors. Type I receptors, found on all lymphohematopoietic cells, are composed of the IL$4 \mathrm{RA}$ and the common gamma chain $(\gamma \mathrm{C})$, which is also a component of IL-2, IL-7, IL-9, IL-15, and IL-21 cytokine receptors [60]. IL-4 receptor type II, also known as the IL13 receptor, is formed by the association of IL-4RA with the IL-13RA subunits and is located on immune cells, bronchial epithelium, and vascular endothelium. IL-4 stimulates both type I and type II receptors, while IL-13 signals through type II receptors.

A potential gain-of-function in the IL-4RA subunit may be responsible for B cell hyperreactivity in ABPA. As a consequence of increased IL-4R activity, proinflammatory cytokines skew $\mathrm{T}$ cell responses to a dominant Th2 pattern which ultimately contributes to the pathophysiology and progression of ABPA. There are eight naturally occurring single nucleotide polymorphisms (SNPs) of the IL4RA gene: ile75val, glu400ala, cys431arg, ser436leu, ser503pro, gln576arg, ser752ala, and ser786pro reported thus far [6171]. Chromosome 16, which has been associated with asthma, contains the IL-4RA gene [66]. Studies have identified a number of these SNPs to be associated with atopy prevalence and asthma severity. In 1997, Hershey et al. [62] initially reported on a high prevalence of atopy and a gainof-function in the IL-4RA as measured by increased CD23 expression in patients with gln576arg and a later study found that this allele correlated with asthma severity [68]. Hershey's group found that the presence of two variants, val75 and arg576 together, resulted in elevated IL-4 dependent CD23 expression which was not observed when these SNPs were present alone [71]. In our studies, the presence of the val75 allele, located within the IL-4 binding region, was found in $87.5 \%$ of ABPA subjects examined, while the cytoplasmic SNPs were present much less frequently at $27.3 \%$ for ala 400 , $27.3 \%$ pro503, $27.3 \% \arg 576$, and $9.1 \% \arg 431$. Although these alleles, particularly val75, appear to be common in the general population, their high prevalence in ABPA suggests that they may be a risk factor in the development of the disease (Table 1).

3.3. IL-10 Polymorphisms. Brouard and coworkers [72] recently in 2005 reported another genetic risk, the association of the -1082GG genotype of the IL-10 promoter with colonization with A. fumigatus and the development of ABPA in CF (Table 1). The - 1082GG polymorphism has been associated with increased IL-10 synthesis, whereas the $-1082 \mathrm{~A}$ allele has lower IL-10 synthesis. Thus, dendritic cells expressing HLA-DR2/DR5, increased IL-10 synthesis and increased sensitivity to IL-4 stimulation due to IL-4RA polymorphisms, may be responsible for skewing Aspergillus-specific Th2 responses in ABPA.

3.4. Surfactant Protein A2 (SP-A2) Polymorphisms. Recently, in 2003, Saxena et al. [73] reported that ABPA patients with polymorphisms (ala91pro and arg94arg) in the collagen region of pulmonary surfactant protein A2 (SP-A2) had more elevated total IgE levels and higher percentages of eosinophilia than observed in those patients who lacked the SNPs (Table 1). They also found that $80 \%$ of patients carrying both alleles had ABPA $(P=0.0079$, OR $=10.4)$, while only $50 \%$ and $60 \%$ of patients carrying each allele, individually, were ABPA subjects, suggesting an additive effect. How these SNPs affect SP-A has not yet been elucidated, but the collagen region spanning both SNPs has been shown to associate with receptors of alveolar macrophages [74], which are important in protecting against Aspergillus colonization [22]. It is theorized that changes in conformation or affinity of SP-A2 may decrease these interactions and compromise host defense.

3.5. Cystic Fibrosis Transmembrane Conductance Regulator (CFTR) Gene Mutations. Because ABPA is found in highest incidence among atopic patients with CF, Miller et al. [75] examined mutations in the cystic fibrosis transmembrane conductance regulator gene (CFTR) in subjects without CF (Table 1). Their group reported that mutations were present at a higher frequency in asthmatic patients who developed 
ABPA, 6 of 21 (28.5\%), versus control asthmatics, 2 of $43(4.6 \%)$. These ABPA patients were heterozygous for the mutations (1 patient was compound heterozygote and reclassified as atypical CF), did not have a clinical diagnosis of CF, and had sweat chlorides $<60 \mathrm{mEq} / \mathrm{L}$. Although the abnormal airway mucus in CF is thought to be a susceptibility factor for ABPA due to enhanced trapping of Aspergillus spores, it is unclear what effect heterozygous CFTR mutations may have on mucus quality in asthmatic airways.

3.6. Toll-Like Receptor (TLR) Polymorphisms. Carvalho et al. [76] examined Toll-like receptor (TLR) polymorphisms of TLR2, TLR4, and TLR9 in cavitary pulmonary aspergillosis (CCPA) and severe asthma associated with fungal sensitization (SAFS). TLR-4 is among the major receptors for Aspergillus hyphae and plays an important part in innate host defense as TLR-4-deficient mice have increased susceptibility to invasive aspergillosis [77]. In CCPA patients, there was significantly increased frequency of the G allele of TLR 4 on asp299gly. ABPA patients had increased frequency of allele $C$ for the TLR9 T-1237C polymorphism compared to control patients. However, in SAFS patients who are predominantly Aspergillus sensitive, there was no association of polymorphisms of TLR2, TLR4, or TLR9. TLR-9 is a receptor that recognizes $C p G$ motifs prevalent in bacterial and viral DNA. Aspergillus hyphae and conidia do signal through TLR-9 on murine neutrophils [78]. TLR-9-deficient mice demonstrate greater conidial and hyphal damage. In addition, Lazarus et al. [79] reported that TLR9 polymorphisms have been associated with increased risk of asthma. Novak et al. [80] reported that the TLR9 C allele of T-1237C decreases expression. Thus, decreased TLR-9 protective function may be an underlying susceptibility in the development of ABPA.

\section{Conclusions}

The prognosis of ABPA is good if the disease is detected early and treatment started promptly. It is important that the diagnosis is made and treatment commenced before there is permanent lung damage from bronchiectasis. In such patients, there should be no progression of the disease, although relapses can occur many years later, and long-term followup is recommended. In children with $\mathrm{CF}$, the relapses seem to be more frequent than they are in patients with asthma, and careful surveillance is necessary to ensure resolution of the disease process. In some CF patients, it is difficult to wean the steroids without an increase in symptoms, such as dyspnea and wheezing, whether this is due to the underlying CF lung disease or due to patients going from stage II to stage III ABPA on withdrawal of steroids is unclear. Adjunctive treatment with antifungal therapy to Aspergillus should be considered. Symptoms are not a reliable guide to therapy; therefore, it is important to reevaluate the chest radiograph and the serum IgE at regular intervals until a long-term remission is established.

ABPA occurs with a worldwide distribution in a significant number of patients with CF and less frequently in those with asthma. Early diagnosis and treatment are essential in preventing end-stage progression. The development of ABPA is probably the combination of many genetic susceptibility factors, gene-gene interactions, and environmental exposure which work together. Understanding of the genetic risks and immunopathogenesis of ABPA hopefully will lead to improved early diagnosis and improved treatment of ABPA.

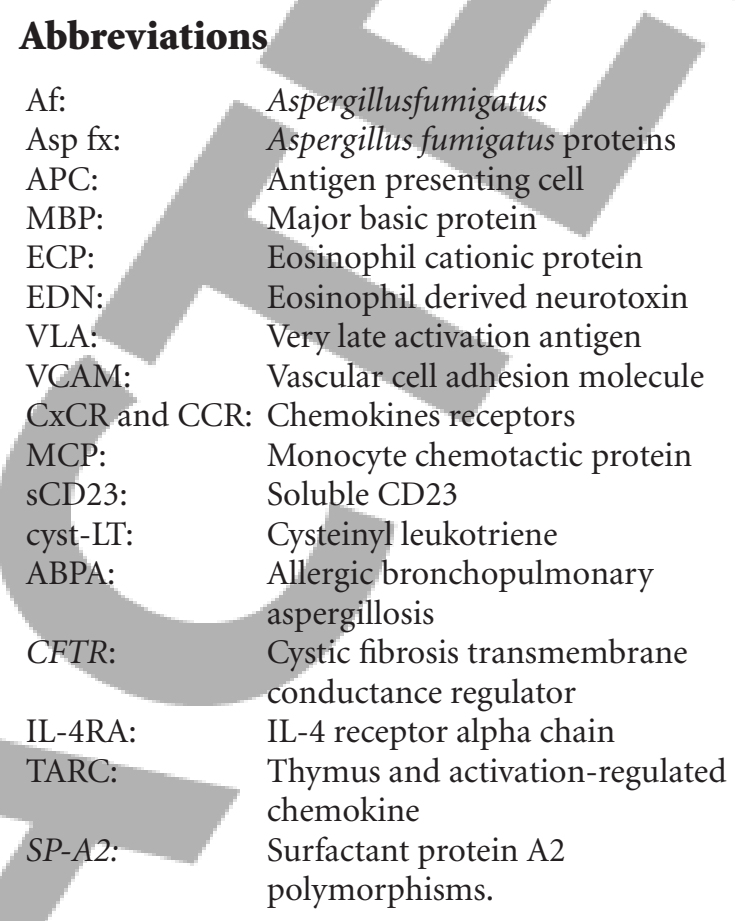

\section{References}

[1] K. Hinson, A. Moon, and N. Plummer, "Broncho-pulmonary aspergillosis," Thorax, vol. 7, pp. 317-333, 1952.

[2] R. Patterson and T. Golbert, "Hypersensitivity disease of the lung," University of Michigan Medical Center Journal, vol. 34, no. 1, pp. 8-11, 1968.

[3] R. G. Slavin, D. J. Stanczyk, A. J. Lonigro, and G. O. Broun Sr., "Allergic bronchopulmonary aspergillosis: a north American rarity," The American Journal of Medicine, vol. 47, no. 2, pp. 306-313, 1969.

[4] A. P. Knutsen, D. R. Mueller, A. D. Levine, B. Chouhan, P. S. Hutcheson, and R. G. Slavin, "Asp fI CD4+ T( $\left.\mathrm{H}_{2}\right)$-like T-cell lines in allergic bronchopulmonary aspergillosis," Journal of Allergy and Clinical Immunology, vol. 94, no. 2, pp. 215-221, 1994.

[5] P. A. Greenberger and R. Patterson, "Allergic bronchopulmonary aspergillosis and the evaluation of the patient with asthma," Journal of Allergy and Clinical Immunology, vol. 81, no. 4, pp. 646-650, 1988.

[6] P. Laufer, J. N. Fink, and W. T. Bruns, "Allergic bronchopulmonary aspergillosis in cystic fibrosis," Journal of Allergy and Clinical Immunology, vol. 73, no. 1 I, pp. 44-48, 1984.

[7] P. A. Greenberger, "Allergic bronchopulmonary aspergillosis," Journal of Allergy and Clinical Immunology, vol. 110, no. 5, pp. 685-692, 2002.

[8] P. A. Greenberger, T. P. Miller, M. Roberts, and L. L. Smith, "Allergic bronchopulmonary aspergillosis in patients with and without evidence of bronchiectasis," Annals of Allergy, vol. 70, no. 4, pp. 333-338, 1993. 
[9] P. A. Greenberger, "Allergic bronchopulmonary aspergillosis," in Allergy: Principles and Practice, N. F. Adkinson Jr., J. W. Yunginger, W. W. Busse, B. S. Bochner, S. T. Holgate, and F. E. R. Simons, Eds., pp. 1353-1371, Mosby, St. Louis, Mo, USA, 2003.

[10] R. Patterson, P. A. Greenberger, R. C. Radin, and M. Roberts, "Allergic bronchopulmonary aspergillosis: staging as an aid to management," Annals of Internal Medicine, vol. 96, no. 3, pp. 286-291, 1982.

[11] D. A. Stevens, R. B. Moss, V. P. Kurup et al., "Allergic bronchopulmonary aspergillosis in cystic fibrosis - state of the art: cystic fibrosis foundation consensus conference," Clinical Infectious Diseases, vol. 37, supplement 3, pp. S225-S264, 2003.

[12] E. Brummer, A. Maqbool, and D. A. Stevens, "Protection of bronchoalveolar macrophages by granulocyte-macrophage colony-stimulating factor against dexamethasone suppression of fungicidal activity for Aspergillus fumigatus conidia," Medical Mycology, vol. 39, no. 6, pp. 509-515, 2001.

[13] S. Hemmann, W. H. Nikolaizik, M. H. Schoni, K. Blaser, and R. Crameri, "Differential IgE recognition of recombinant Aspergillus fumigatus allergens by cystic fibrosis patients with allergic bronchopulmonary aspergillosis or Aspergillus allergy, European Journal of Immunology, vol. 28, no. 4, pp. 11551160, 1998.

[14] P. Latzin, D. Hartl, N. Regamey, U. Frey, M. H. Schoeni, and C. Casaulta, "Comparison of serum markers for allergic bronchopulmonary aspergillosis in cystic fibrosis," European Respiratory Journal, vol. 31, no. 1, pp. 36-42, 2008.

[15] D. Hartl, P. Latzin, G. Zissel, M. Krane, S. Krauss-Etschmann, and M. Griese, "Chemokines indicate allergic bronchopulmonary aspergillosis in patients with cystic fibrosis," American Journal of Respiratory and Critical Care Medicine, vol. 173, no. 12, pp. 1370-1376, 2006.

[16] R. G. Slavin, C. W. Bedrossian, P. S. Hutcheson et al., "A pathologic study of allergic bronchopulmonary aspergillosis," Journal of Allergy and Clinical Immunology, vol. 81, no. 4, pp. 718-725, 1988.

[17] A. P. Knutsen, "Immunopathogenesis of allergic bronchopulmonary aspergillosis," Frontiers in Bioscience, vol. 8, pp. 589602, 2003.

[18] A. P. Knutsen, "Genetic risk factors in the development of allergic bronchopulmonary aspergillosis," Current Trends in Immunology, vol. 7, pp. 47-54, 2006.

[19] A. P. Knutsen, B. Kariuki, L. Santiago et al., "HLA-DR, IL-4RA, and IL-10: genetic risk factors in allergic bronchopulmonary aspergillosis," Pediatric Asthma, Allergy and Immunology, vol. 21, no. 4, pp. 185-190, 2009.

[20] H. F. Kauffman, J. F. Christomee, M. A. van de Riet, A. J. Timmerman, and P. Borger, "Protease-dependent activation of epithelial cells by fungal allergens leads to morphologic changes and cytokine production," Journal of Allergy and Clinical Immunology, vol. 105, no. 6, pp. 1185-1193, 2000.

[21] J. F. Tomee, H. F. Kauffman, A. H. Klimp, J. G. de Monchy, G. H. Köeter, and A. E. Dubois, "Immunologic significance of a collagen-derived culture filtrate containing proteolytic activity in Aspergillus-related diseases," Journal of Allergy and Clinical Immunology, vol. 93, no. 4, pp. 768-778, 1994.

[22] A. Schaffner, H. Douglas, and A. Braude, "Selective protection against conidia by mononuclear and against mycelia by polymorphonuclear phagocytes in resistance to aspergillus: observations on these two lines of defense in vivo and in vitro with human and mouse phagocytes," Journal of Clinical Investigation, vol. 69, no. 3, pp. 617-631, 1982.
[23] E. Roilides, K. Uhlig, D. Venzon, P. A. Pizzo, and T. J. Walsh, "Prevention of corticosteroid-induced suppression of human polymorphonuclear leukocyte-induced damage of Aspergillus fumigatus hyphae by granulocyte colony-stimulating factor and gamma interferon," Infection and Immunity, vol. 61, no. 11, pp. 4870-4877, 1993.

[24] E. Brummer, A. Maqbool, and D. A. Stevens, "In vivo granulocyte macrophage colony-stimulating factor prevents dexamethasone suppression of killing of Aspergillus fumigatus by broncho-alveolar macrophages," Journal of Leukocyte Biology, vol. 70, pp. 868-872, 2001.

[25] H. K. Kauffman and J. F. Tomee, "Inflammatory cells and airway defense against Aspergillus fumigatus," Immunology and Allergy Clinics of North America, vol. 18, no. 3, pp. 619-640, 1998.

[26] J. F. Tomee and H. F. Kauffman, "Putative virulence factors of Aspergillus fumigatus," Clinical and Experimental Allergy, vol. 30, no. 4, pp. 476-484, 2000.

[27] J. F. Tomee, A. T. J. Wierenga, P. S. Hiemstra, and H. F. Kauffman, "Proteases from Aspergillus fumigatus induce release of proinflammatory cytokines and cell detachment in airway epithelial cell lines," Journal of Infectious Diseases, vol. 176, no. 1, pp. 300-303, 1997.

[28] J. F. Tomee, T. S. van der Werf, J. P. Latge, G. H. Koeter, A. E. Dubois, and H. F. Kauffman, "Serologic monitoring of disease and treatment in a patient with pulmonary aspergilloma," American Journal of Respiratory and Critical Care Medicine, vol. 151, no. 1, pp. 199-204, 1995.

[29] L. Gu, S. Tseng, R. M. Horner, C. Tam, M. Loda, and B. J. Rollins, "Control of $\mathrm{T}_{H} 2$ polarization by the chemokine monocyte chemoattractant protein-1," Nature, vol. 404, no. 6776, pp. 407-411, 2000.

[30] C. G. Persson, J. S. Erjefalt, I. Erjefalt, M. C. Kursgren, M. C. Nilsson, and F. Sundler, "Epithelial shedding-restitution as a causative process in airway inflammation," Clinical and Experimental Allergy, vol. 26, no. 7, pp. 746-755, 1996.

[31] A. P. Knutsen, B. Chauhan, and R. G. Slavin, "Cell-mediated immunity in allergic bronchopulmonary aspergillosis," Immunology and Allergy Clinics of North America, vol. 18, no. 3, pp. 575-599, 1998.

[32] S. P. Khan, J. S. McClellan, and A. P. Knutsen, "Increased sensitivity to IL-4 in patients with allergic bronchopulmonary aspergillosis," International Archives of Allergy and Immunology, vol. 123, no. 4, pp. 319-326, 2000.

[33] A. P. Knutsen, P. S. Hutchinson, G. M. Albers, J. Consolino, J. Smick, and V. P. Kurup, "Increased sensitivity to IL-4 in cystic fibrosis patients with allergic bronchopulmonary aspergillosis," Allergy, vol. 59, no. 1, pp. 81-87, 2004.

[34] A. P. Knutsen, B. Kariuki, J. D. Consolino, and M. R. Warrier, "IL-4 alpha chain receptor (IL-4R $\alpha$ ) polymorphisms in allergic bronchopulmonary sspergillosis," Clinical and Molecular Allergy, vol. 4, article 3, 2006.

[35] A. P. Knutsen, "Genetic and respiratory tract risk factors for aspergillosis: ABPA and asthma with fungal sensitization," Medical Mycology, vol. 44, supplement 1, pp. S61-S70, 2006.

[36] R. Crameri, S. Hemmann, C. Ismail, G. Menz, and K. Blaser, "Disease-specific recombinant allergens for the diagnosis of allergic bronchopulmonary aspergillosis," International Immunology, vol. 10, no. 8, pp. 1211-1216, 1998.

[37] H. J. Schwartz, K. M. Citron, E. H. Chester et al., "A comparison of the prevalence of sensitization to Aspergillus antigens among asthmatics in Cleveland and London," Journal of Allergy and Clinical Immunology, vol. 62, no. 1, pp. 9-14, 1978. 
[38] E. A. Valletta, C. Braggion, and G. Mastella, "Sensitization to Aspergillus and allergic bronchopulmonary Aspergillosis in a cystic fibrosis population," Pediatric Asthma, Allergy and Immunology, vol. 7, no. 1, pp. 43-49, 1993.

[39] A. P. Knutsen and R. G. Slavin, "In vitro T cell responses in patients with cystic fibrosis and allergic bronchopulmonary aspergillosis," Journal of Laboratory and Clinical Medicine, vol. 113, no. 4, pp. 428-435, 1989.

[40] R. G. Slavin, P. S. Hutcheson, and A. P. Knutsen, "Participation of cell-mediated immunity in allergic bronchopulmonary aspergillosis," International Archives of Allergy and Applied Immunology, vol. 83, no. 4, pp. 337-340, 1987.

[41] A. P. Knutsen, K. R. Mueller, P. S. Hutcheson, and R. G. Slavin, "T- and B-cell dysregulation of IgE synthesis in cystic fibrosis patients with allergic bronchopulmonary aspergillosis," Clinical Immunology and Immunopathology, vol. 55, no. 1, pp. 129 $138,1990$.

[42] B. A. Chauhan, A. P. Knutsen, P. S. Hutcheson, R. G. Slavin, and C. J. Bellone, "T cell subsets, epitope mapping, and HLArestriction in patients with allergic bronchopulmonary aspergillosis," Journal of Clinical Investigation, vol. 97, no. 10, pp. 2324-2331, 1996.

[43] L. B. Bacharier and R. S. Geha, "Molecular mechanisms of IgE regulation," Journal of Allergy and Clinical Immunology, vol. 105, supplement 2, pp. S547-S558, 2000.

[44] V. P. Kurup, B. W. Seymour, H. Choi, and R. L. Coffman, "Particulate Aspergillus fumigatus antigens elicit a $\mathrm{T}_{H 2}$ response in $\mathrm{BALB} / \mathrm{c}$ mice," Journal of Allergy and Clinical Immunology, vol. 93, no. 6, pp. 1013-1020, 1994.

[45] R. P. Schleimer, S. A. Sterbinsky, C. A. Kaiser et al., "IL-4 induces adherence of human eosinophils and basophils but not neutrophils to endothelium: association with expression of VCAM-1," Journal of Immunology, vol. 148, no. 4, pp. 10861092, 1992.

[46] R. Moser, J. Fehr, and P. L. Bruijnzeel, "IL-4 controls the selective endothelium-driven transmigration of eosinophils from allergic individuals," Journal of Immunology, vol. 149, no. 4, pp. 1432-1438, 1992.

[47] J. Y. Bonnefoy, J. F. Gauchat, P. Life, P. Graber, J. P. Aubry, and S. Lecoanet-Henchoz, "Regulation of IgE synthesis by CD23/CD21 interaction," International Archives of Allergy and Immunology, vol. 107, no. 1-3, pp. 40-42, 1995.

[48] J. Y. Bonnefoy, J. F. Gauchat, P. Life, P. Graber, G. Mazzei, and J. P. Aubry, "Pairs of surface molecules involved in human IgE regulation: CD23-CD21 and CD40-CD40L," European Respiratory Journal, Supplement, vol. 9, supplement 22, pp. 63S-66S, 1996.

[49] L. J. Rosenwasser, W. W. Busse, R. G. Lizambri, T. A. Olejnik, and M. C. Totoritis, "Allergic asthma and an anti-CD23 mAb (IDEC-152): results of a phase I, single-dose, dose-escalating clinical trial," Journal of Allergy and Clinical Immunology, vol. 112, no. 3, pp. 563-570, 2003.

[50] D. Vercelli, H. H. Jabara, K. I. Arai, and R. S. Geha, "Induction of human IgE synthesis requires interleukin 4 and T/B cell interactions involving the $\mathrm{T}$ cell receptor/CD3 complex and MHC class II antigens," Journal of Experimental Medicine, vol. 169, no. 4, pp. 1295-1307, 1989.

[51] J. Punnonen, G. Aversa, B. G. Cocks et al., "Interleukin 13 induces interleukin 4-independent IgG4 and IgE synthesis and CD23 expression by human B cells," Proceedings of the National Academy of Sciences of the United States of America, vol. 90, no. 8, pp. 3730-3734, 1993.
[52] T. Defrance, P. Carayon, G. Billian et al., "Interleukin 13 is a B cell stimulating factor," Journal of Experimental Medicine, vol. 179, no. 1, pp. 135-143, 1994.

[53] B. Chauhan, L. Santiago, D. A. Kirschmann et al., "The association of HLA-DR alleles and T cell activation with allergic bronchopulmonary aspergillosis," Journal of Immunology, vol. 159, no. 8, pp. 4072-4076, 1997.

[54] J. R. Lamb, J. A. Higgins, C. Hetzel, J. D. Hayball, R. A. Lake, and R. E. O'Hehir, “The effects of changes at peptide residues contacting MHC class II T-cell receptor on antigen recognition and human Th0 cell effector function," Immunology, vol. 85, no. 3, pp. 447-454, 1995.

[55] D. C. Tsitoura, A. Verhoef, C. M. Gelder, R. E. O'Hehir, and J. R. Lamb, "Altered T cell ligands derived from a major house dust mite allergen enhance IFN- $\gamma$ but not IL-4 production by human CD4 $4^{+}$T cells," Journal of Immunology, vol. 157, no. 5, pp. 2160-2165, 1996.

[56] C. Pfeiffer, J. Stein, S. Southwood, H. Ketelaar, A. Sette, and K. Bottomly, "Altered peptide ligands can control CD4 T lymphocyte differentiation in vivo," Journal of Experimental Medicine, vol. 181, no. 4, pp. 1569-1574, 1995.

[57] B. D. Evavold, J. Sloan-Lancaster, B. L. Hsu, and P. M. Allen, "Separation of $\mathrm{T}$ helper 1 clone cytolysis from proliferation and lymphokine production using analog peptides," Journal of Immunology, vol. 150, no. 8, pp. 3131-3140, 1993.

[58] L. Racioppi, F. Ronchese, L. A. Matis, and R. N. Germain, "Peptide-major histocompatibility complex class II complexes with mixed agonist/antagonist properties provide evidence for ligand-related differences in $\mathrm{T}$ cell receptor-dependent intracellular signaling," Journal of Experimental Medicine, vol. 177, no. 4, pp. 1047-1060, 1993.

[59] K. Nelms, A. D. Keegan, J. Zamorano, J. J. Ryan, and W. E. Paul, "The IL-4 receptor: signaling mechanisms and biologic functions," Annual Review of Immunology, vol. 17, pp. 701738, 1999.

[60] T. Habib, A. Nelson, and K. Kaushansky, "IL-21: a novel IL2-family lymphokine that modulates B, T, and natural killer cell responses," Journal of Allergy and Clinical Immunology, vol. 112, no. 6, pp. 1033-1045, 2003.

[61] G. K. Khurana Hershey, "IL-13 receptors and signaling pathways: an evolving web," Journal of Allergy and Clinical Immunology, vol. 111, no. 4, pp. 677-690, 2003.

[62] G. K. Hershey, M. F. Friedrich, L. A. Esswein, M. L. Thomas, and T. A. Chatila, "The association of atopy with a gainof-function mutation in the $\alpha$ subunit of the interleukin-4 receptor," New England Journal of Medicine, vol. 337, no. 24, pp. 1720-1725, 1997.

[63] K. Deichmann, J. Bardutzky, J. Forster, A. Heinzmann, and J. Kuehr, "Common polymorphisms in the coding part of the IL4-Receptor gene," Biochemical and Biophysical Research Communications, vol. 231, no. 3, pp. 696-697, 1997.

[64] S. Kruse, T. Japha, M. Tedner et al., "The polymorphisms S503P and Q576R in the interleukin-4 receptor $\alpha$ gene are associated with atopy and influence the signal transduction," Immunology, vol. 96, no. 3, pp. 365-371, 1999.

[65] C. Ober, S. A. Leavitt, A. Tsalenko et al., "Variation in the interleukin 4-receptor $\alpha$ gene confers susceptibility to asthma and atopy in ethnically diverse populations," American Journal of Human Genetics, vol. 66, no. 2, pp. 517-526, 2000.

[66] K. A. Deichmann, A. Heinzmann, J. Forster et al., "Linkage and allelic association of atopy and markers flanking the IL4receptor gene," Clinical and Experimental Allergy, vol. 28, no. 2, pp. 151-155, 1998. 


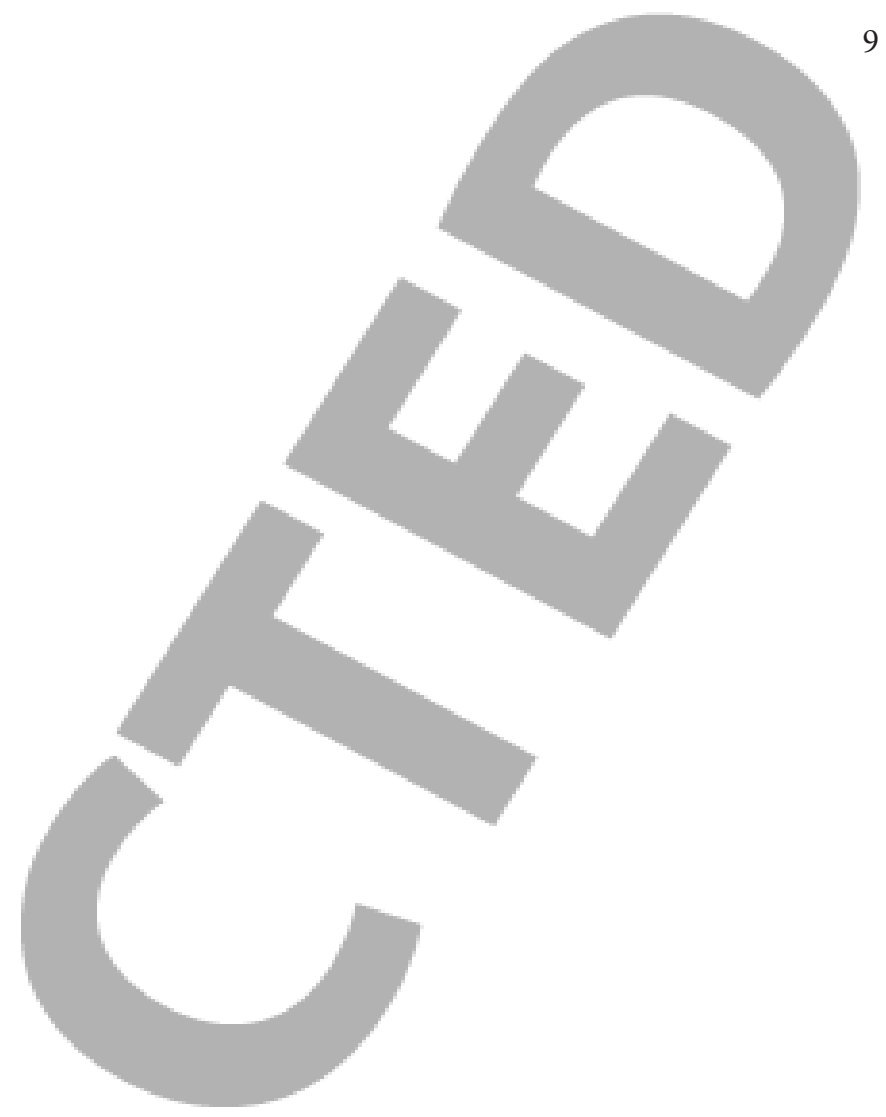

[67] H. Mitsuyasu, K. Izuhara, X. Q. Mao et al., "Ile50Val variant of IL4R alpha upregulates IgE synthesis and associates with atopic asthma," Nature Genetics, vol. 19, no. 2, pp. 119-120, 1998.

[68] L. Rosa-Rosa, N. Zimmermann, J. A. Bernstein, M. E. Rothenberg, and G. K. Khurana Hershey, "The R576 IL-4 receptor allele correlates with asthma severity," Journal of Allergy and Clinical Immunology, vol. 104, no. 5, pp. 1008-1014, 1999.

[69] E. Noguchi, M. Shibasaki, T. Arinami et al., "No association between atopy/asthma and the Ile50Val polymorphism of IL4 receptor," American Journal of Respiratory and Critical Care Medicine, vol. 160, no. 1, pp. 342-345, 1999.

[70] H. Mitsuyasu, Y. Yanagihara, X. Q. Mao et al., "Cutting edge: dominant effect of Ile50Val variant of the human IL-4 receptor $\alpha$-chain in IgE synthesis," Journal of Immunology, vol. 162, no. 3, pp. 1227-1231, 1999.

[71] K. A. Risma, N. Wang, R. P. Andrews et al., "V75R576 IL-4 receptor $\alpha$ is associated with allergic asthma and enhanced IL4 receptor function," Journal of Immunology, vol. 169, no. 3, pp. 1604-1610, 2002.

[72] J. Brourad, N. Knauer, P. Y. Boelle et al., "Influence of interleukin-10 on airways colonization by Aspergillus fumigatus in cystic fibrosis patients," Journal of Infectious Diseases, vol. 191, pp. 1988-1991, 2005.

[73] S. Saxena, T. Madan, A. Shah, K. Muralidhar, and P. A. Sarma, "Association of polymorphisms in the collagen region of SP-A2 with increased levels of total IgE antibodies and eosinophilia in patients with allergic bronchopulmonary aspergillosis," Journal of Allergy and Clinical Immunology, vol. 111, no. 5, pp. 1001-1007, 2003.

[74] L. F. Weikert, K. Edwards, Z. C. Chroneos et al., "SP-A enhances uptake of bacillus Calmette-Guerin by macrophages through a specific SP-A receptor," American Journal of Physiology, vol. 272, no. 5, pp. L989-L995, 1997.

[75] P. W. Miller, A. Hamosh, M. Macek Jr. et al., "Cystic fibrosis transmembrane conductance regulator (CFTR) gene mutations in allergic bronchopulmonary aspergillosis," American Journal of Human Genetics, vol. 59, no. 1, pp. 45-51, 1996.

[76] A. Carvalho, A. C. Pasqualotto, L. Pitzurra, L. Romani, D. W. Denning, and F. Rodrigues, "Polymorphisms in toll-like receptor genes and susceptibility to pulmonary aspergillosis," Journal of Infectious Diseases, vol. 197, no. 4, pp. 618-621, 2008.

[77] J. E. Wang, A. Warris, E. A. Ellingsen et al., "Involvement of CD14 and toll-like receptors in activation of human monocytes by Aspergillus fumigatus hyphae," Infection and Immunity, vol. 69, no. 4, pp. 2402-2406, 2001.

[78] S. Bellocchio, S. Moretti, K. Perruccio et al., "TLRs govern neutrophil activity in aspergillosis," Journal of Immunology, vol. 173, no. 12, pp. 7406-7415, 2004.

[79] R. Lazarus, W. T. Klimecki, B. A. Raby et al., "Single-nucleotide polymorphisms in the Toll-like receptor 9 gene (TLR9): frequencies, pairwise linkage disequilibrium, and haplotypes in three U.S. ethnic groups and exploratory case-control disease association studies," Genomics, vol. 81, no. 1, pp. 85-91, 2003.

[80] N. Novak, C. F. Yu, C. Bussmann et al., "Putative association of a TLR9 promoter polymorphism with atopic eczema," Allergy, vol. 62, no. 7, pp. 766-772, 2007.

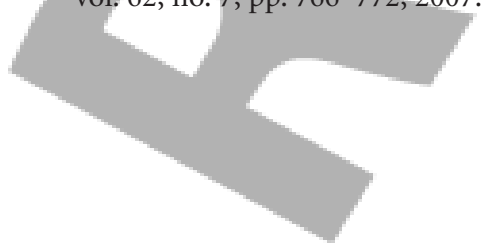

